\title{
Selective determination of urea using urease immobilized on $\mathrm{ZnO}$ nanowires
}

\author{
Syed Usman Ali, Zafar Hussain Ibupoto, Salah Salman, Omer Nur,
} Magnus Willander and Bengt Danielsson

\section{Linköping University Post Print}

N.B.: When citing this work, cite the original article.

Original Publication:

Syed Usman Ali, Zafar Hussain Ibupoto, Salah Salman, Omer Nur, Magnus Willander and Bengt Danielsson, Selective determination of urea using urease immobilized on $\mathrm{ZnO}$ nanowires, 2011, Sensors and actuators. B, Chemical, (160), 1, 637-643.

http://dx.doi.org/10.1016/j.snb.2011.08.041

Copyright: Elsevier http://www.elsevier.com/

Postprint available at: Linköping University Electronic Press

http://urn.kb.se/resolve?urn=urn:nbn:se:liu:diva-74860 


\title{
Selective determination of urea using urease immobilized on $\mathrm{ZnO}$ nanowires
}

\author{
Syed M. Usman Ali ${ }^{1}{ }^{*}$, Zafar Hussain Ibupoto ${ }^{1}$, Salah Salman ${ }^{2}$, Omer Nur ${ }^{1}$, Magnus \\ Willander ${ }^{1}$, Bengt Danielsson ${ }^{2}$ \\ ${ }^{1}$ Physical Electronics and Nanotechnology Division, Department of Science and Technology, \\ Campus Norrköping, Linköping University, SE-60174 Norrköping, Sweden. \\ ${ }^{2}$ Acromed Invest AB, Magistratsvägen 10, SE-22643 Lund, Sweden
}

\begin{abstract}
Well-aligned zinc oxide $(\mathrm{ZnO})$ nanowire arrays were fabricated on gold-coated plastic substrates using a low-temperature aqueous chemical growth (ACG) method. The ZnO nanowire arrays with $50-130 \mathrm{~nm}$ diameters and $\sim 1 \mu \mathrm{m}$ in lengths were used in an enzymebased urea sensor through immobilization of the enzyme urease that was found to be sensitive to urea concentrations from $0.1 \mathrm{mM}$ to $100 \mathrm{mM}$. Two linear sensitivity regions were observed when the electrochemical responses (EMF) of the sensors were plotted vs. the logarithmic concentration range of urea from $0.1 \mathrm{mM}$ to $100 \mathrm{mM}$. The proposed sensor showed a sensitivity of $52.8 \mathrm{mV} /$ decade for $0.1-40 \mathrm{mM}$ urea and a fast response time less than $4 \mathrm{~s}$ was achieved with good selectivity, reproducibility and negligible response to common interferents such as ascorbic acid and uric acid, glucose, $\mathrm{K}^{+}$and $\mathrm{Na}^{+}$ions.
\end{abstract}

Index Terms: ZnO-nanowire arrays, electrochemical nanodevices, urease enzyme and urea determination.

\section{*Corresponding author.}

Email address: syeal@itn.liu.se 


\section{Introduction}

Urea is an important marker for studies of renal function. The normal level of urea in serum is from 15 to $40 \mathrm{mg} / \mathrm{dl}$ (or $1.7-8.3 \mathrm{mM}$ ) and level increases up to $100 \mathrm{mM}$ under pathophysiological conditions [1]. An increase in urea level in blood and urine can be caused by renal failure, urinary tract obstruction, dehydration, shock, burns, and gastrointestinal bleeding. Moreover, reduced urea level may be seen in hepatic failure, nephritic syndrome, and cachexia. Determination of blood urea nitrogen is an important routine test widely used in clinical laboratories. Several types of biosensors [2-5] are used for the detection and estimation of urea based on urease. Urease is an important part in most enzymatic sensors evolution to fulfil the growing requirement for the urea determination. Although colorimetric and spectrometric methods are most commonly used [6-7], these methods are laborious and not suitable for on line monitoring system. This inconvenience was overcome by using electrochemical technique of sensing because electrochemical biosensors provide an attractive means to analyze the content of a biological sample due to the direct conversion of a biological event to an electric signal. The inherent advantages of electrochemical biosensors are their robustness, easy miniaturization, excellent detection limits, also with small analyte volumes and ability to be used in turbid biofluids with optically absorbing and fluorescing compounds [8-9]. Moreover, due to the unique properties of nanostructures/nanomaterials in the biosensing area, nanosensors offer some significant advantages owing to their small size and high surface area to volume ratios allowing larger signals, better catalysis and the more rapid movement of analytes through sensors. Recently, nanostructured materials such as zinc oxide $(\mathrm{ZnO})$ [10-14], cerium oxide $\left(\mathrm{CeO}_{2}\right)$ [15], tin oxide $\left(\mathrm{SnO}_{2}\right)$ [16], titanium oxide $\left(\mathrm{TiO}_{2}\right)$ [17], iron oxide $\left(\mathrm{FeO}_{2}\right)$ [18] and zirconium oxide $\left(\mathrm{ZrO}_{2}\right)$ nanoparticles [19] have been used for fabrication of transducer surface because of their unique ability to promote faster electron transfer between electrode and active site of desired enzyme. Among these nanomaterials, 
$\mathrm{ZnO}$ nanostructures receive growing attention due to their unique properties including high specific surface area, high catalytic efficiency, strong adsorption ability, high isoelectric point (IEP 9.5), wide band gap (3.37 eV), biocompatibility and high electron communication features. Moreover, the high IEP of $\mathrm{ZnO}$ is advantageous for immobilizing enzymes with low IEP through electrostatic interactions as reported in our earlier investigations for uric acid and glucose detection $[10,13]$. Furthermore, nontoxicity, high chemical stability and high electron transfer capability make $\mathrm{ZnO}$ a promising material for immobilization of biomolecules involved in electron or charge transfer without need for electron mediators [20]

In the present work, we have successfully demonstrated the potentiometric determination of urea by using $\mathrm{ZnO}$ nanowire arrays fabricated on the gold-coated plastic substrates by using a low-temperature aqueous chemical growth (ACG) method. Urease was immobilized on the surface of the $\mathrm{ZnO}$ nanowires using a simple electrostatic process. The potentiometric response vs. the $\mathrm{Ag} / \mathrm{AgCl}$ reference electrode was found to be linear over a logarithmic concentration range of 0.1 to $100 \mathrm{mM}$ suitable for the common urea levels in blood serum. The proposed sensor $(\mathrm{Urs} / \mathrm{ZnO} / \mathrm{Au})$ has a fast response time of less than $4 \mathrm{~s}$ and retained good enzymatic activity for more than three weeks when kept at $4{ }^{0} \mathrm{C}$ temperature when not in use.

\section{Experimental details}

\subsection{Materials and reagent}

Urease (E.C. 3.5.1.5 from jack bean $100 \mathrm{U} / \mathrm{mg}$ ), Urea (ACS reagent.99.9 \%), uric acid (Purity was $99.8 \%), \beta$-D-glucose (99.5\%), zinc nitrate hexahydrate and hexamethylenetetramine were purchased from Sigma Aldrich. Phosphate Buffer, $10 \mathrm{mM}$ solution (PBS) was prepared from $\mathrm{Na}_{2} \mathrm{HPO}_{4}$ and $\mathrm{KH}_{2} \mathrm{PO}_{4}$ (Sigma Aldrich) with sodium chloride in $0.135 \mathrm{mM}$ and the $\mathrm{pH}$ was adjusted to 7.4. A stock urea solution of $100 \mathrm{mM}$ was prepared in PBS, and stored at $4{ }^{0} \mathrm{C}$. The low concentration standard solutions of urea were freshly prepared before the measurements. All chemicals used (Sigma, Aldrich) were of analytical reagent grade. 


\subsection{Fabrication of $\mathrm{ZnO}$ nanowire arrays on gold coated plastic substrate}

To fabricate the $\mathrm{ZnO}$ nanowire arrays on the flexible plastic substrate, first the substrate was cleaned with acetone, isopropanol and de-ionized water. After cleaning, a titanium thin film with $20 \mathrm{~nm}$ thicknesses was evaporated as an adhesive layer on plastic substrate and then gold (Au) thin film with $100 \mathrm{~nm}$ thickness was evaporated on it. To obtain well-aligned hexagonal $\mathrm{ZnO}$ nanowire arrays on the electrode surface, we followed the low temperature ACG method described in [21]. In the ACG method, substrates were spin-coated with seed solution and annealed at $100{ }^{\circ} \mathrm{C}$ for 10 minutes. The seed solution consisted of $0.025 \mathrm{M}$ zinc nitrate hexahydrate $\left[\left(\mathrm{Zn}\left(\mathrm{NO}_{3}\right)_{2} 6 \mathrm{H}_{2} \mathrm{O}\right)\right]$ mixed with $0.0025 \mathrm{M}$ hexamethylenetetramine $\left[\mathrm{C}_{6} \mathrm{H}_{12} \mathrm{~N}_{4}\right]$ in water. The substrates were placed in the seed solution using Teflon sample holders and kept in an oven at $90{ }^{\circ} \mathrm{C}$ for $2-5$ hours. A small part of the gold-coated plastic substrates were covered to be used as contact area. After the growth was completed, the nanowires were cleaned in de-ionized water and dried at room temperature. A typical SEM image of $\mathrm{ZnO}$ nanowires grown using this procedure is shown in figure 1(a). It can be seen from the SEM image that the $\mathrm{ZnO}$ nanowires were $50-130 \mathrm{~nm}$ in diameter and $\sim 1 \mu \mathrm{m}$ in length with uniform density and spatial distribution. The nanowires were perpendicular relative to the surface of the substrate. The morphological and structural characteristics of the grown nanowires can be controlled by adjusting the growth process parameters such as the concentration of the seed solution, the reagent stoichiometry, the temperature and the $\mathrm{pH}$ of the growth solution [22].

\subsection{Immobilization of urease on the $\mathrm{ZnO}$-nanowires and measurements}

Before the immobilization of urease enzyme on the surface of the $\mathrm{ZnO}$-nanowires electrode, the electrodes were rinsed with PBS to generate a hydrophilic surface. A urease solution was prepared in phosphate buffer solution (PBS, $10 \mathrm{mM}, \mathrm{pH} 7.4$ ) containing $5 \mathrm{mg}$ of urease per $\mathrm{ml}$. 
In order to optimize the electrostatic adsorption and retained catalytic activity of urease, electrodes were immersed in the urease solution for different time intervals like 10 minutes, 20 minutes, 30 minutes, 60 minutes and 3 hours at room temperature and left in air for 30 minute to dry. It was found that an immersion time of 20 minutes was quite satisfactory to form a uniform irreversible layer of urease with stable response. Shorter immersion time resulted in incomplete immobilization with certain leakage of enzyme molecules and poor sensor response. ZnO-nanowires with immobilized urease are shown in figure 1(b). After completing these steps, the sensors were initially checked potentiometrically in different concentrations of urea solutions with an $\mathrm{Ag} / \mathrm{AgCl}$ reference electrode $(3 \mathrm{M} \mathrm{KCl}$ as filling solution) purchased from Metrohm (Switzerland). The measurements were carried out by a potentiometric method utilising two electrodes. ZnO-nanowires based electrode coated with enzyme served as the working electrode and an $\mathrm{Ag} / \mathrm{AgCl}$ electrode was used as the reference electrode. A pH meter (Model 215, Denver Instrument) was used to measure the potentiometric output voltage of the sensors presented here. For the time response measurements, a model 363A potentiostat/galvanostat (EG \& G, USA) was used. All enzyme electrodes were stored in dry condition at $4{ }^{0} \mathrm{C}$ when not in use.

\section{Results and discussion}

\subsection{Sensing mechanism and electrochemical measurements}

The elemental composition of the as-grown $\mathrm{ZnO}$ nanowires was analyzed by energy dispersive X-rays spectroscopy as shown in figure $1(\mathrm{~d})$. The peaks are attributed to the zinc $(\mathrm{Zn})$ and oxygen $(\mathrm{O})$ elements while the peaks from gold $(\mathrm{Au})$ are attributed to the substrate. These results gave evidence that the $\mathrm{ZnO}$ nanowires were free from impurities. Most electrochemical urea sensors are based on an enzymatic reaction catalyzed by urease. Figure 2 describes the sensing mechanism of the proposed urea sensor using immobilized urease on $\mathrm{ZnO}$-nanowires. It is known that urea can react directly with bare $\mathrm{ZnO}$ nanowires and 
hydrolyse, but the rate of the hydrolysis is not at all up to the extent of enzymatic hydrolysis. The rate of urea hydrolysis with bare $\mathrm{ZnO}$ nanowires is slow and unpredictable and not reproducible whereas the reaction rate of urea hydrolysis on the surface of $\mathrm{ZnO}$ nanowires with immobilized urease is fast, repeatable and produces a reproducible electrochemical response. Moreover, enzymatic urea detection is generally based on determining the products of urea based hydrolysis formed in accordance with equation (1) given below.

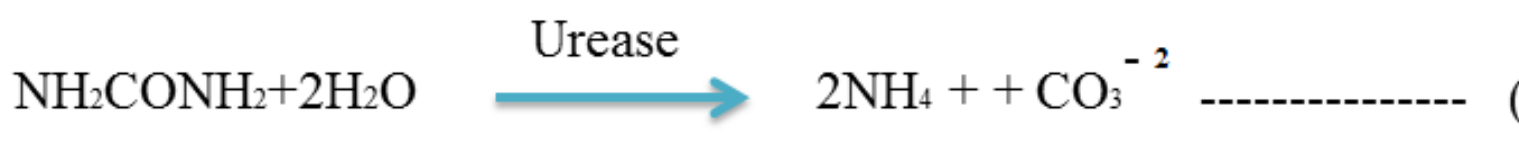

As a result of this reaction one $\mathrm{HCO}_{3}{ }^{-}$and two $\mathrm{NH}_{4}{ }^{+}$ions produced from the uncharged urea. The ammonium ions react with the $\mathrm{ZnO}$ nanowire array and produce the corresponding EMF change of the output of the sensor. The electrochemical measurements were carried out using a two-electrode configuration consisting of the urease coated $\mathrm{ZnO}$ nanowires sensor as the working electrode and an $\mathrm{Ag} / \mathrm{AgCl}$ reference electrode. The electrochemical response was measured at room temperature $(23 \pm 2){ }^{0} \mathrm{C}$ with the electrodes immersed in the samples in a stirred small glass vessels. There are only few reports about the urea sensing with $\mathrm{ZnO}$ as a matrix and then only using amperometric methods [23-24]. In this work, we demonstrate a simple two-electrode potentiometric method for the urea measurement using urease immobilized on $\mathrm{ZnO}$ nanowire arrays. The sensor as fabricated is highly sensitive and showed sensitivity of $52.8 \mathrm{mv} /$ decade to the concentration changes of urea test solutions. The operational linear range and the stability of the sensors were evaluated potentiometrically in urea solutions made in buffer (PBS pH 7.4) with concentration ranging from $0.1 \mathrm{mM}$ to $100 \mathrm{mM}$ as shown in figure 3 (a). The tested sensor configuration showed very interesting data which can be divided into two regions. The electrochemical response (EMF) that was linear vs. the logarithmic concentration of urea going from $0.1 \mathrm{mM}$ to $40 \mathrm{mM}$ 
(region 1) and $50 \mathrm{mM}$ to $100 \mathrm{mM}$ (region 2) respectively as shown in the figure 3(b). The first region (region 1) in figure 3 (b) includes the wide linear range from $0.1 \mathrm{mM}$ to $40 \mathrm{mM}$. This range is suitable for the detection of the urea because the normal level of urea is below 10 $\mathrm{mM}$. The second region (region 2) indicates that the same proposed sensor can detect higher concentrations of urea i.e. up to $100 \mathrm{mM}$ with proper calibration although the underlying reason for the abnormal response is not fully understood. In region 1 the $\mathrm{ZnO}$-nanowire arrays sensor approximately followed the Nernst's expression

$$
E=E_{0}-0.05916 \mathrm{~V} / \mathrm{n} \log [\text { Reduced] / [Oxidized] }
$$

The proposed sensor has exhibited a very fast response time noted over the whole concentration range with $95 \%$ of the steady state voltage (EMF) achieved within $\sim 4 \mathrm{~s}$. The calibration curve showing the sequential addition of urea solutions in a buffer solution is shown in figure 4. It is very important to note that $\mathrm{ZnO}$-nanowire arrays are relatively stable around $\mathrm{pH} 7.4$ and this gives these sensors good bio-compatibility in biological fluids and species since most of the biological fluids are around $\mathrm{pH}$ of 7.4. The morphology of the sensor surface was checked by scanning electron microscopy (SEM) right after measurements as shown in figure in figure 1 (c).

\subsection{Sensor reproducibility, stability, measuring range and detection limit}

The properties of a biosensor can be characterized by parameters like reproducibility, measuring range, detection limit, response time and selectivity etc. The reproducibility is an important characteristic for the performance evaluation of a biosensor. To evaluate reproducibility characteristic and long term stability of the proposed sensors, we fabricated 8 sensors electrodes independently under the same conditions and immobilized the urease enzyme on $\mathrm{ZnO}$ nanowires arrays. Due to high isoelectric point (IEP) of $\mathrm{ZnO}(\sim 9.5)$ and low IEP $(\sim 5.0)$ of urease, the proposed sensor retained its enzymatic activity due to their strong 
electrostatic interaction and could be reused several times with proper cleaning in a span of 23 hours. The sensor response in $10 \mathrm{mM}$ urea solution was more than $90 \%$ reproducible till eight times reused as shown in figure 5(a). The relative standard deviation of the fabricated sensor electrode in standard urea solutions was less than $5 \%$. To evaluate the operational and storage stability of the proposed sensors we have kept the sensors at $4{ }^{0} \mathrm{C}$ and periodically tested them for more than three weeks; they retained up to $80 \%$ of their original activity and still showed a good response to urea as shown in figure 5 (b). The measuring range of the proposed sensor was obtained from the linear part of the calibration curves as shown in figure 3(a). The applicable measuring range of the proposed sensor is between $0.1 \mathrm{mM}$ to $40 \mathrm{mM}$. By extrapolating the linear parts of the calibration curve, the detection limit of the sensor electrode can be calculated. In the present work, the detection limit of the sensor was $0.1 \mathrm{mM}$ which was calculated by the extrapolating of the two segments of the calibration curve shown in figure $3(b)$.

\subsection{Selectivity of the $\mathrm{ZnO}$ nanowires arrays based sensor}

Selectivity is the most important characteristic which describes the specificity towards the target ion in the presence of other ions (interfering ions). There are different methods to determine selectivity of the potentiometric sensors [25]. These methods are such as the separate solution method, the mixed solution method, the matched potential method, and the unbiased selective coefficients. Instead of using the above mentioned methods, we checked the selectivity and stability of the sensor by output response curve. The possible interferences present in blood that may interfere with a urea biosensor include ascorbic acid (AA) uric acid (UR), glucose (GL) and potassium $\left(\mathrm{K}^{+}\right)$and sodium $\left(\mathrm{Na}^{+}\right)$ions [26]. Hence, ascorbic acid, uric acid, glucose, $\left(\mathrm{K}^{+}\right)$and $\left(\mathrm{Na}^{+}\right)$ions were selected to affirm the selectivity of the proposed urea sensor. In the present work, upon adding of100 $\mu \mathrm{M}$ ascorbic acid, $5 \mathrm{mM}$ glucose, $100 \mu \mathrm{M}$ uric acid, $5 \mathrm{mM}\left(\mathrm{Na}^{+}\right)$and $5 \mathrm{mM}(\mathrm{K}+)$ solutions in a $1 \mathrm{mM}$ urea solution 
only minor signal changes were observed and this is probably due to instability/disturbance caused by the successive addition of the solutions as shown figure 6 . This was repeated several times on new, independently prepared sensors and continued to show negligible signal response to interferences. In practical measurements, however these changes in sensor response can be neglected.

\section{Effect of $\mathrm{pH}$ and temperature}

The objective of this study is to determine the appropriate $\mathrm{pH}$ measurement environment for the newly fabricated $\mathrm{ZnO}$ nanowire arrays based urea biosensor. The $\mathrm{pH}$ of the working medium affects the activity of the urease based urea hydrolysis and the signal response (EMF) of the sensor electrode. The $\mathrm{pH}$ dependence of sensor response was investigated in $10 \mathrm{mM}$ urea solution over the $\mathrm{pH}$ range from 4.5 to 9.5 as shown in figure $7(\mathrm{a})$. The experimental results indicate that the maximum signal response of proposed urea sensor was obtained between 6.5 to $7.5 \mathrm{pH}$. Moreover, at $\mathrm{pH}$ value higher than 8 , the potential decreases due to the solubility of $\mathrm{ZnO}$ at $\mathrm{pH} \geq 8$ [27] and precipitation of urea hydrolysis reaction. Thus, our experimental results showed that the performance of the urea sensors was stable at $\mathrm{pH}$ around 7.4.

The effect of varying temperature on the sensor response in $20 \mathrm{mM}$ urea solution was also examined between 20 and $80{ }^{\circ} \mathrm{C}$. As shown in Fig 7 (b), the response (EMF) gradually increases with increasing of temperature and reaches to its maximum value at around $50{ }^{0} \mathrm{C}$. This is because at $50{ }^{0} \mathrm{C}$ the enzyme has optimum activity [28]. After $50{ }^{0} \mathrm{C}$, the response decreases which is caused by the natural thermal degradation of the enzymes. However, the biosensor has showed a maximum response at around $50{ }^{\circ} \mathrm{C}$. But during the experiments, it has been observed that at temperature around $50{ }^{0} \mathrm{C}$ the response of the sensor although at maximum was not well stable while at room temperature it was quite stable and exhibited good long term performance. Moreover, it has also been observed that when we tried to test 
the sensor at $50{ }^{\circ} \mathrm{C}$ then the enzymatic activity degraded drastically and showed poor long term performance. Therefore, room temperature $(23 \pm 2){ }^{0} \mathrm{C}$ was chosen for this work in order to prevent possible solution evaporation, enzyme degradation at higher temperature and ease of operation.

\section{Conclusion}

In this study, we have demonstrated a simple fabrication procedure for a highly sensitive urea biosensor based on $\mathrm{ZnO}$ nanowire arrays which provided a suitable microenvironment for enzyme loading and an easy immobilization procedure. The proposed sensor retained its enzymatic activity due to strong electrostatic interaction between zinc oxide and urease. The proposed biosensor showed a fast response with less than $4 \mathrm{~s}$ and has a quite wide linear range which is divided into two linear regions that includes from $0.1 \mathrm{mM}$ to $40 \mathrm{mM}$ (region 1) and from $50 \mathrm{mM}$ to $100 \mathrm{mM}$ (region 2) respectively. During the experiments, the sensor exhibited good performance in sensitivity, stability, selectivity, reproducibility and negligible interference to the common interferents. All these advantageous features can make the proposed biosensor applicable in medical, food or other areas. The proposed device can also be employed to on-spot clinical diagnosis. It is also convenient to assemble into portable chip based sensing devices suitable to unskilled users. Moreover, the fabrication method is simple and can be extended to immobilize other enzymes and other bioactive molecules with low isoelectric points for a variety of biosensor designs. 


\section{Figure 1}

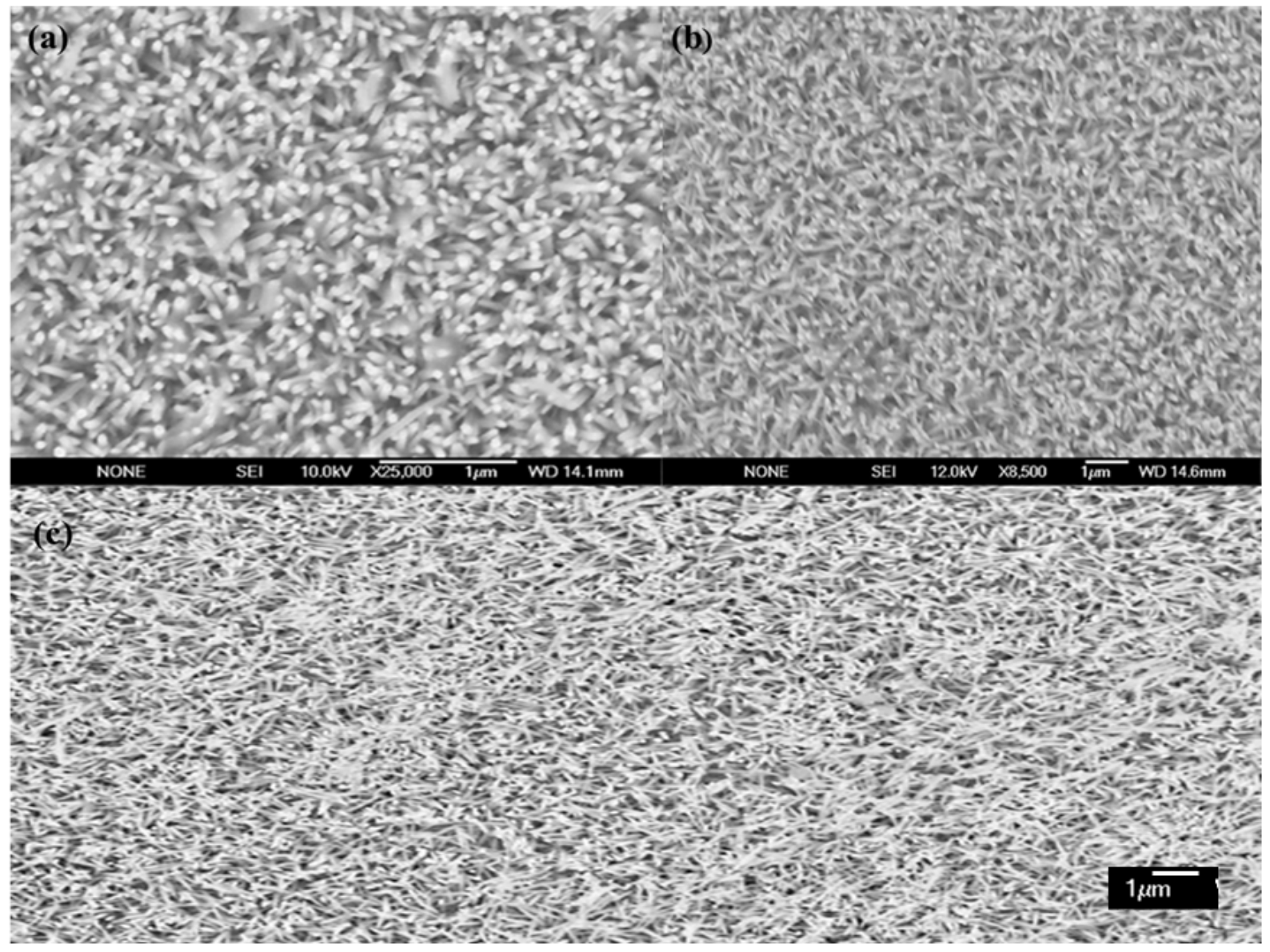

(d) 


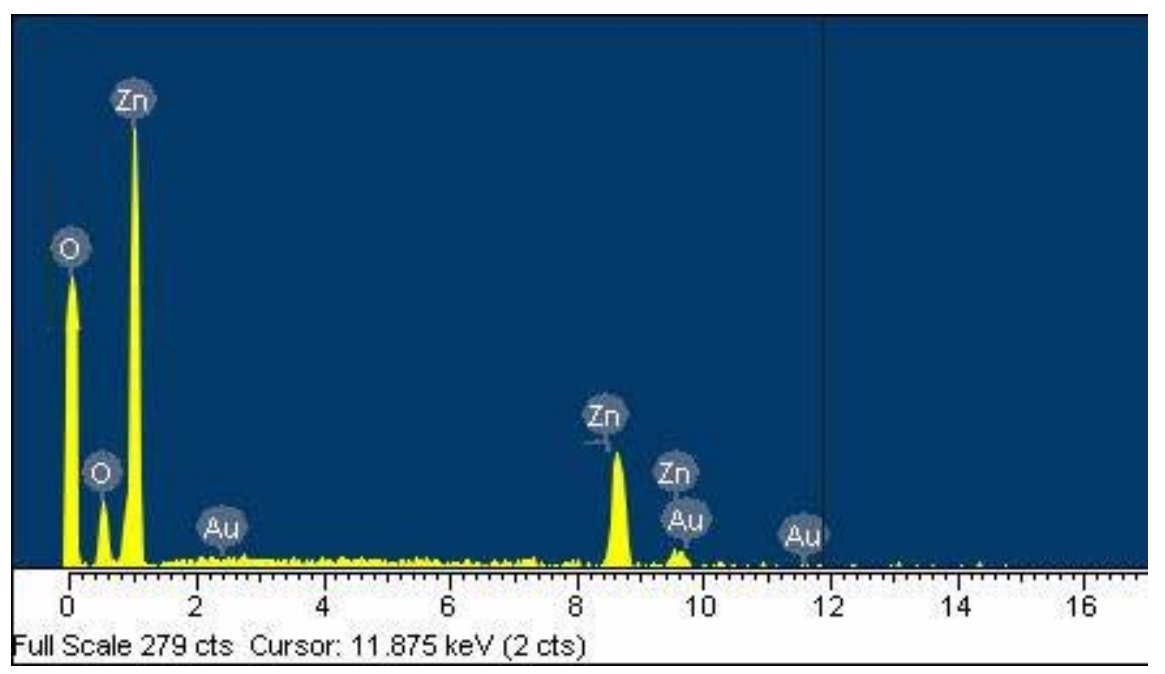

Figure 2

Schematic illustration for the urea sensing setup using $\mathrm{ZnO}$-nanowires with immobilized urease as working electrode and $\mathrm{Ag} / \mathrm{AgCl}$ as reference electrode.

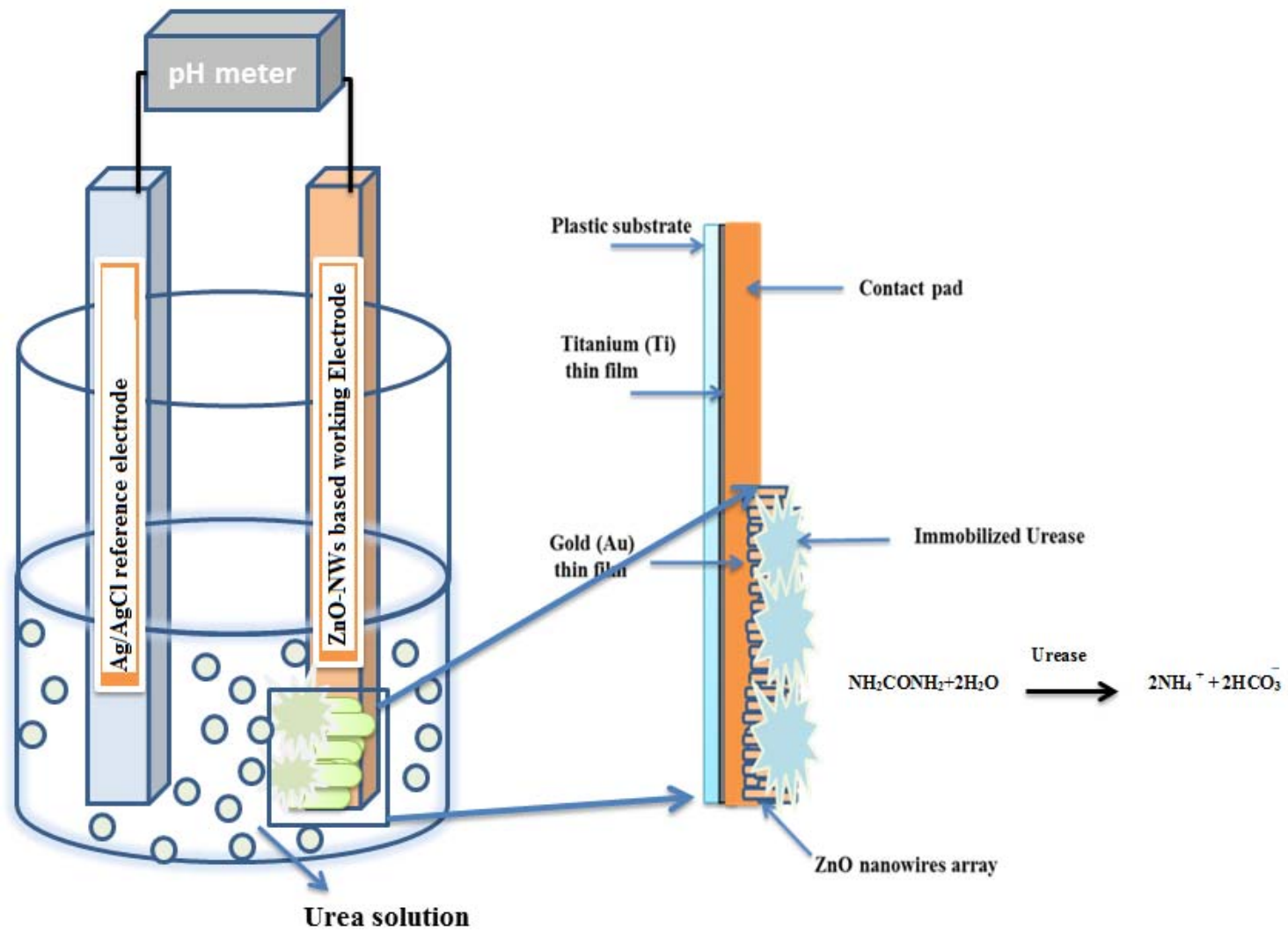


Figure 3
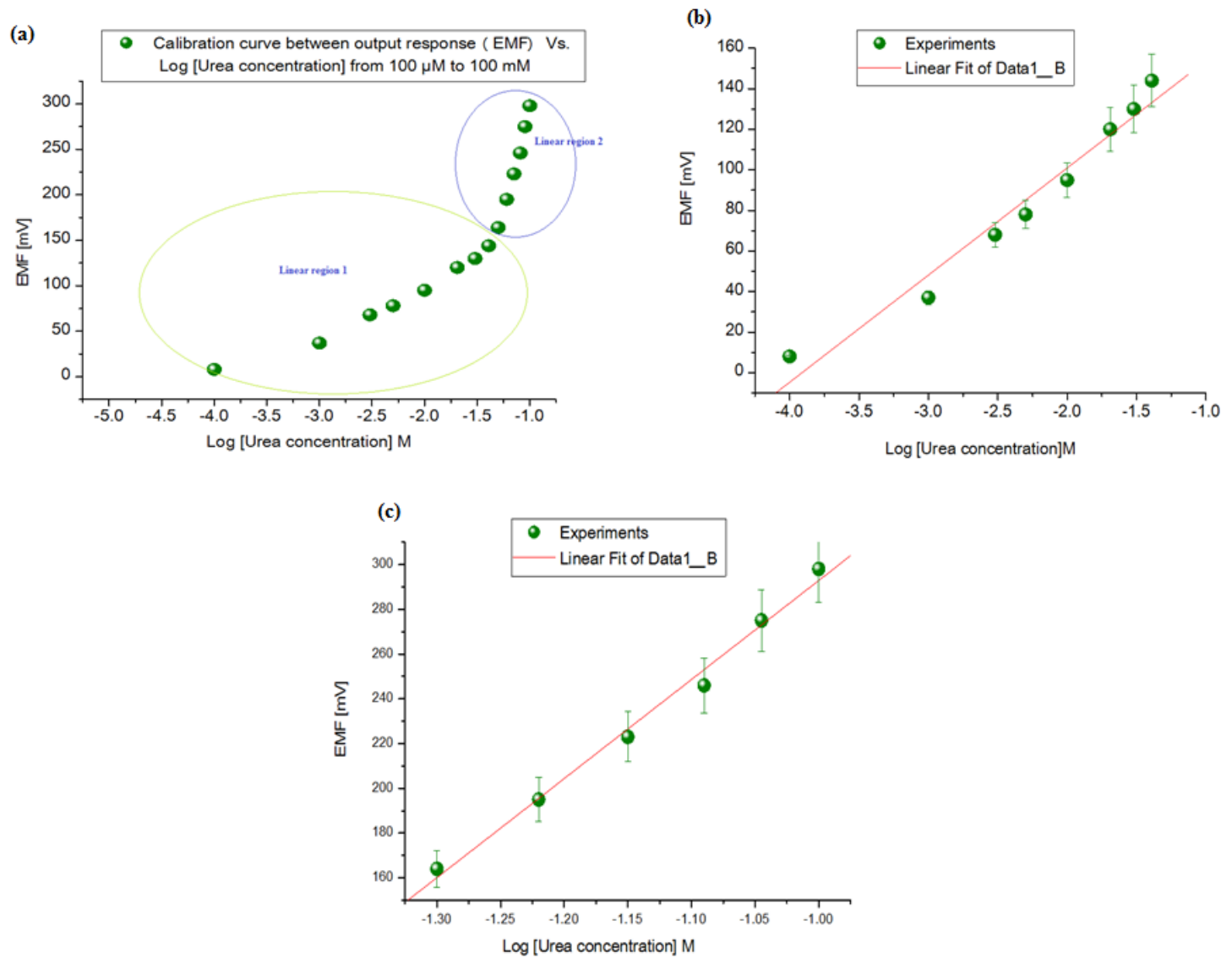
Figure 4

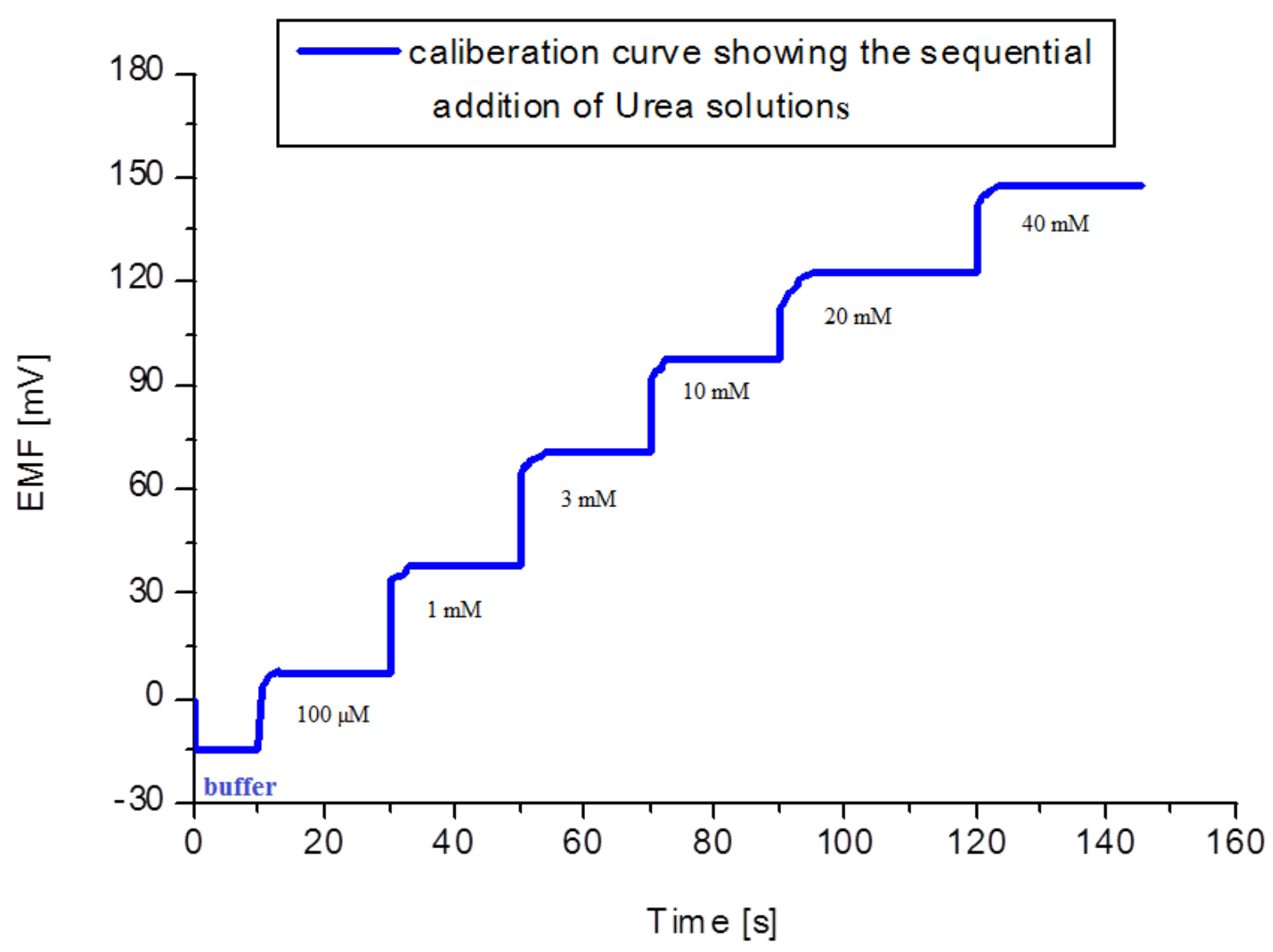


Figure 5

(a)

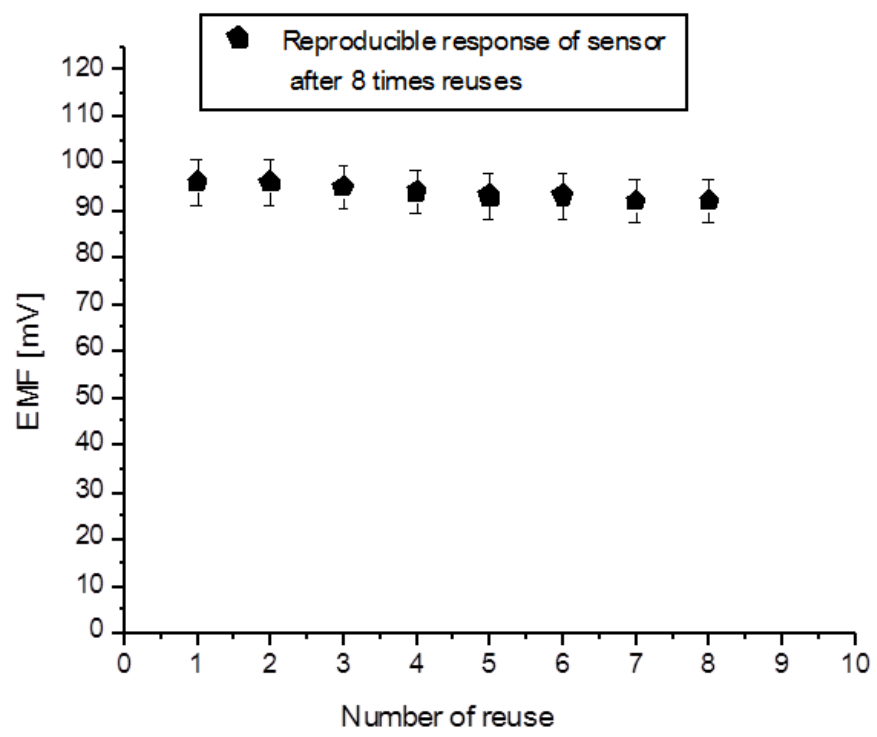

(b)

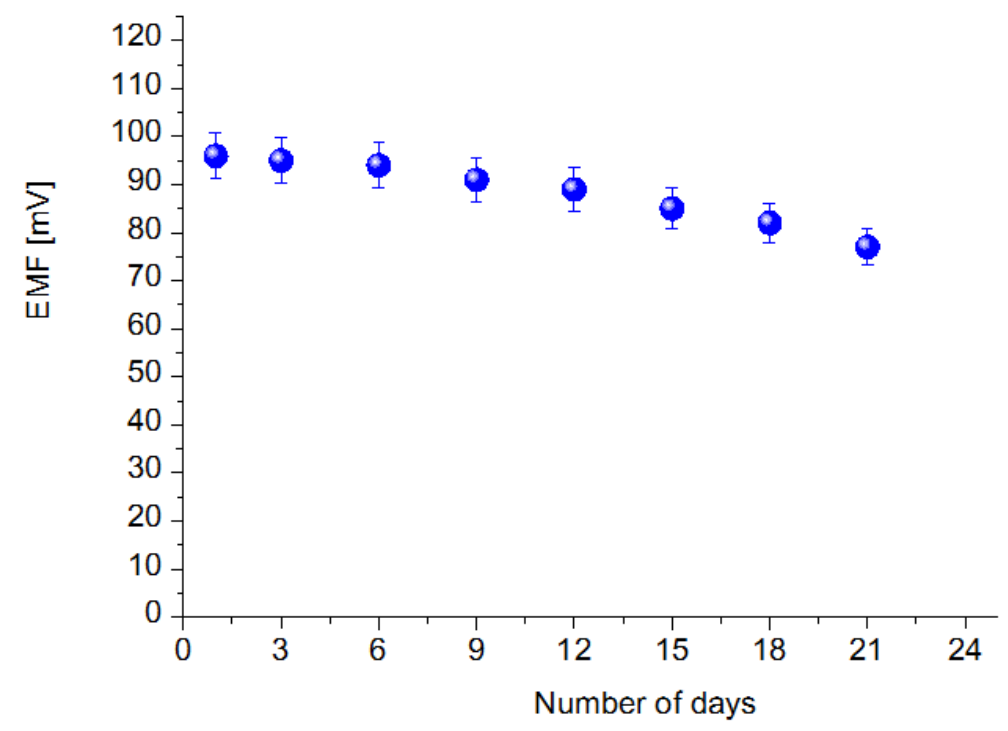


Figure 6

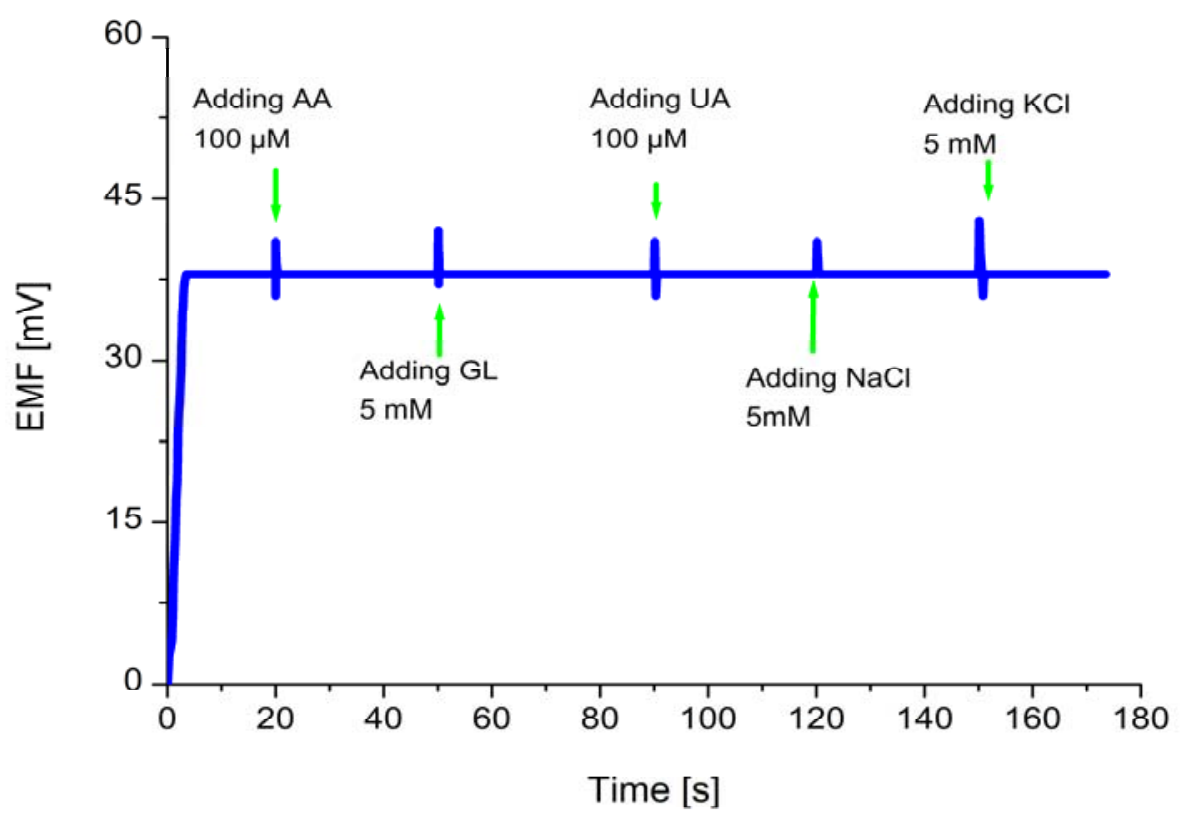


Figure 7

(a)

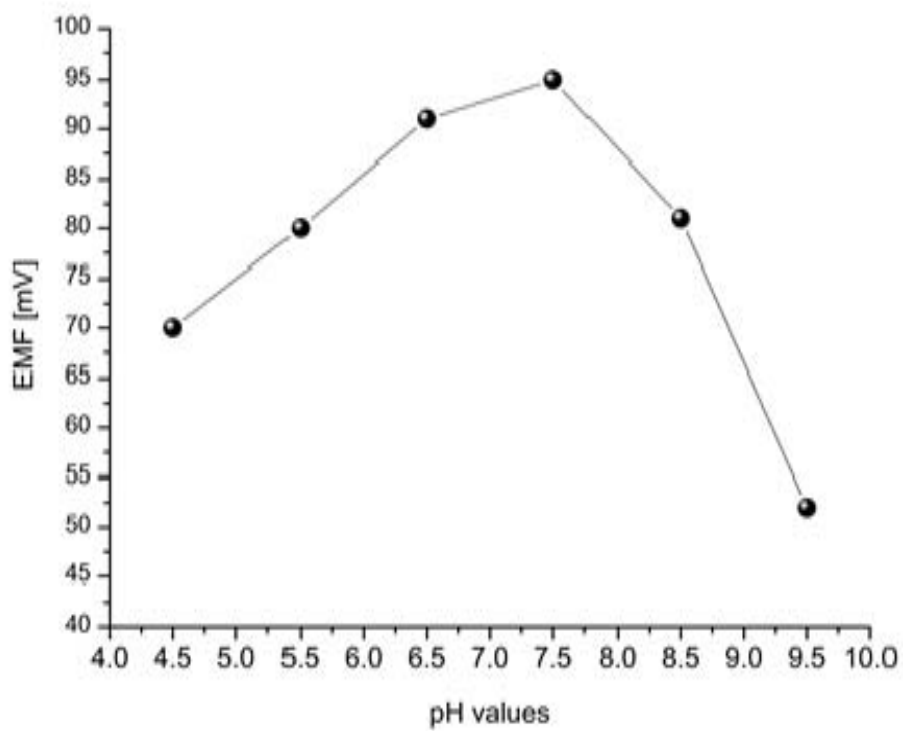

(b)

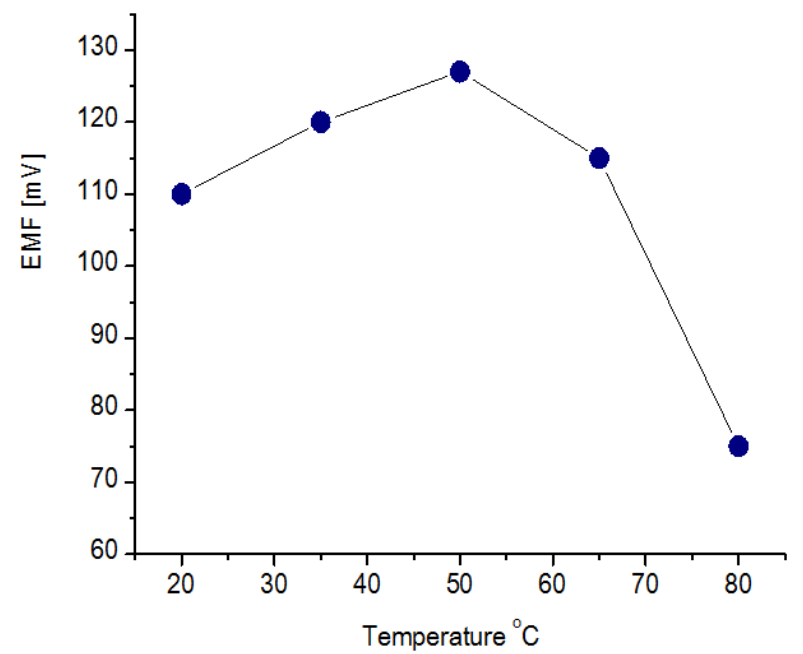




\section{Figure Captions}

Fig. 1(a-d): Typical scanning electron microscopy (SEM) images of $\mathrm{ZnO}$ nanowires grown on gold coated plastic substrate using low temperature chemical growth. Figure (a) showing the $\mathrm{ZnO}$-nanowires without urease immobilization and (b) with urease immobilization (c) same sensor after measurements and (d) energy dispersive x-ray spectroscopic spectrum of $\mathrm{ZnO}$ nanowires grown on gold coated plastic.

Fig. 2: Schematic diagram for the urea sensing set up using urease coated $\mathrm{ZnO}$ nanowires as working electrode and $\mathrm{Ag} / \mathrm{AgCl}$ as reference electrode with possible electrochemical reaction near the working electrode.

Fig. 3(a-c): Calibration curves using urease coated $\mathrm{ZnO}$-nanowires sensor electrode showing the electrochemical response (EMF) at different urea concentrations $(0.1 \mathrm{mM}$ to $100 \mathrm{mM})$ with $\mathrm{Ag} / \mathrm{AgCl}$ reference electrode (a) Calibration curve between output response (EMF) vs. Log of urea concentrations (b) Calibration curve of linear region 1 (c) Calibration curve of linear region 2 .

Fig. 4: Calibration curves showing the sequential addition of urea solutions.

Fig. 5: (a) Calibration curve showing the urease coated $\mathrm{ZnO}$ nanowires sensor reproducibility/ reusability at room temperature after 2-3 hours span in $10 \mathrm{mM}$ urea solution (b) Calibration curve showing the study of response (EMF) with the influence of storage at $4^{0} \mathrm{C}$ for three weeks.

Fig. 6: Calibration curve showing the study of interferences with time trace line of Output response (EMF) change with time after adding $100 \mu \mathrm{M}$ ascorbic acid (AA), $5 \mathrm{mM}$ glucose (GL) , $100 \mu \mathrm{M}$ uric acid (UA), $5 \mathrm{mM} \mathrm{NaCl}$ and $5 \mathrm{mM} \mathrm{KCl}$ solutions as an interfering substances in $1 \mathrm{mM}$ urea solution. 
Fig. 7: (a-b): Calibration curves showing the study of EMF response with the influence of varying temperature and $\mathrm{pH}$ values. 


\section{References:}

[1] W. Rick, Klinische Chemie und Mikroskopie. Berlin: Springer-Verlag; 1990. p. 245-247.

[2] S.G. Ansari, Z. A. Ansari, H. K. Seo, G. S. Kim, Y. S. Kim, G. Khang, H. S. Shin, Urea sensor based on tin oxide thin films prepared by modified plasma enhanced CVD, Sens. Actuators B 132(2008) 265-271.

[3] P. R. Solanki, A. Kaushik, A.A. Ansari, G. Sumana and B. D. Malhotra, ZnO oxidechitosan nanobiocomposite for urea sensor, Appl. Phys. Lett. 93(2008) 163903-163906.

[4] A. P. Soldatkin, J. Montoriol, W. Sant, C. Martelet, N. J. Renault, A novel urea sensitive biosensor with extended dynamic range based on recombinant urease and ISFETs, Biosens. Bioelectron. 19(2003) 131-135.

[5] S. K. Jha, A. Topkar, S. F. D’Souza, Development of potentiometric urea biosensor based on urease immobilized in PVA-PAA composite matrix for estimation of blood urea nitrogen (BUN), J. Biochem. Biophys. Methods 70(2008) 1145-1150.

[6] H. L. Rosenthal, Determination of urea in blood and urine with diacetyl monoxime, Anal. Chem. 27 (1955) 1980-1982.

[7] B. Xie, U. Harborn, M. Mecklenburg and B. Danielsson, Urea and lactate determined in 1uL whole blood with a miniaturized thermal biosensor. Clin. Chem. 40 (1994) 2282-2287.

[8] M. S. Wilson, Electrochemical immunosensors for the simultaneous detection of two tumor markers, Anal. Chem. 77 (2005) 1496-1502.

[9] P. D’Orazio, Biosensors in clinical chemistry, Clin. Chim. Acta. 334 (2003) 41-69. 
[10] S. M. Usman Ali, N.H. Alvi, Z. Ibupoto, O. Nur, M. Willander, B. Danielsson, Selective potentiometric determination of uric acid with uricase Immobilized on $\mathrm{ZnO}$ nanowires, Sens. Actuators B Chem. 2 (2011) 241-247.

[11] S. M. Usman Ali, M.H. Asif , A. Fulati , O. Nur, M. Willander, C. Brännmark, P. Strålfors, U. H. Englund, F. Elinder and B. Danielsson, Intracellular $\mathrm{K}^{+}$determination with a potentiometric microelectrode based on $\mathrm{ZnO}$ nanowires, Nanotechnology, IEEE Transaction on , $10(2011)$ 913-919.

[12] S. M. Usman Ali, O. Nur, M. Willander and B. Danielsson, Glucose detection with a commercial MOSFET using a $\mathrm{ZnO}$ nanowires extended gate, Nanotechnology, IEEE Transaction on, 8 (2009) 678-683.

[13] S. M. Usman Ali, O. Nur, M. Willander, B. Danielsson, A fast and sensitive potentiometric glucose microsensor based on glucose oxidase coated $\mathrm{ZnO}$ nanowires grown on a thin silver wire, Sens. Actuators B Chem. 145 (2010) 869-874.

[14] M. H. Asif, S. M. Usman Ali, O. Nur, M. Willander, C. Brännmark, P. Strålfors , U. Englund, F. Elinder and B. Danielsson, Functionalized ZnO nanorod based intracellular glucose sensor, Biosens. Bioelectron. 25 (2010) 2205-2211.

[15] A. A. Ansari, P. R. Solanki, B. D. Malhotra, Sol-gel derived nanostructured cerium oxide film for glucose sensor, Appl. Phys. Lett. 92 (2008) 263901-263903.

[16] E. Topoglidis, Y. Astuti, F. Duriaux, M. Gratzel, J. R. Durrant, Direct electrochemistry and nitric oxide interaction of heme proteins adsorbed on nanocrystalline tin oxide electrodes, Langmuir. 19 (2003) 6894-6900.

[17] J. Yu, H. Ju, Preparation of porous titania sol-gel matrix for immobilization of horseradish peroxidase by a vapor deposition method, Anal. Chem.74 (2002) 3579-3583. 
[18] A. Kaushik, P. R. Solanki, A. A. Ansari, S. Ahmad, B. D. Malhotra, Chitosan-iron oxide nanobiocomposite based immunosensor for ochratoxin-A Electrochem. Commun. 10(2008)1364-1368.

[19] P. R. Solanki A. Kaushik , P.M. Chavhan , S.N. Maheshwari , B. D. Malhotra, Nanostructured zirconium oxide based genosensor for Escherichia coli detection, Electrochem. Commun. 11 (2009) 2272-2277.

[20] Z. Liu, Y. Liu, H. Yang, Y. Yang, G, Shen, R. Yu, A Mediator-Free Tyrosinase Biosensor Based on ZnO Sol-Gel Matrix, Electroanalysis, 17 (2005) 1065-70.

[21] N. H. Alvi, S. M. Usman Ali, S. Hussain, O. Nur, and M. Willander, Fabrication and comparative optical characterization of $\mathrm{n}-\mathrm{ZnO}$ nanostructures (nanowalls, nanorods, nanoflowers and nanotubes)/p-GaN white light emitting diodes, Scripta Materialia 64 (2011) $697-700$.

[22] H .Zhang, D Yang, S. Li, X. Ma, Y. Ji, J. Xu, D. Qu, Controllable growth of ZnO nanostructures by citric acid assisted hydrothermal process, Mater. Lett. 59 (2005) 1696 1700.

[23] A. Ali, A. A. Ansari, A. Kaushik, P. R. Solanki, A. Barik, M. K. Pandey, B. D. Malhotra, nanostructured zinc oxide film for urea sensor, Mater. Lett. 63(2009) 2473-2475.

[24] S. G. Ansari, R. Wahab, Z. A. Ansari, Y. S. Kim, G. Khang, A. Al-Hajry, H. S. Shin, Effect of nanostructure on the urea sensing properties of sol-gel synthesized $\mathrm{ZnO}$, Sens. Actuators B Chem. 137 (2009) 566-573

[25] M.R. Ganjali, P. Norouzi and M. Rezapour, Encyclopedia of Sensors; Potentiometric Ion Sensors, American Scientific Publisher (ASP), Los Angeles: 8 (2006) 197-288. 
[26] J. W. Luo, M. Zhang, D. W. Pang, Selective and sensitive determination of uric acid at DNA-modified graphite powder microelectrodes, Sens. Actuators B Chem. 106 (2005) 358362.

[27] A. Fulati, S. M. Usman Ali, M. Riaz, G. Amin, O. Nur and M. Willander, Miniaturized pH sensors based on zinc oxide nanotubes/nanorods, Sensors 9 (2009) 8911-892.

[28] A. Arullan, C. A. Sastry, M. A. Hashim, Immobilization of urease on vermiculite, Bioprocess Engg. 16(1997) 375-380. 


\section{Corresponding author: Syed M. Usman Ali}

E-mail: syeal@itn.liu.se;

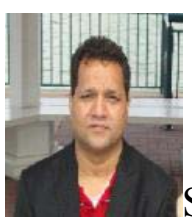

Syed Muhammad Usman Ali received the B.E degree in Electronic Engineering from (DCET) NED University of Engineering \& Technology Karachi, Pakistan in 1993 and the M Sc. (Electrical Engineering) in Power electronics and computer systems in 2000 from NED university of Engineering \& Technology Karachi, Pakistan. Syed M. Usman Ali is an assistant Professor in Department of Electronic Engineering at NED University of Engineering and Technology Karachi, Pakistan. He is currently a $\mathrm{PhD}$ scholar in the Department of Science and Technology, (Physical Electronics and Nanotechnology Division) Campus Norrköping, Linköping University, SE-601 74 Norrköping, Sweden. His current research interests are based on $\mathrm{ZnO}$ nano-structures characterization and device development for technical and medical applications. $\mathrm{He}$ is also involved in the fabrication and characterization of micro and nano photonics devices (Nanoelectronics).

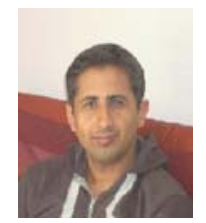

Zafar Hussain Ibupoto did M.Sc in Physical Chemistry in 2001 from S.A.L University, Khairpur Mirs, Sindh, Pakistan. Zafar Hussain Ibupoto is working as a lecturer in Dr. M.A Kazi Institute of Chemistry, University of Sindh, Jamshoro, Pakistan. He is currently joined as a PhD student in the Department of science and Technology, (Physical Electronics and Nanotechnology Division) campus Norrköping, Linköping University, SE-601 74 Norrköping, Sweden. His ongoing research interests are based on $\mathrm{ZnO}$ nanostructures characterization and medical applications based on $\mathrm{ZnO}$ nanomaterials.

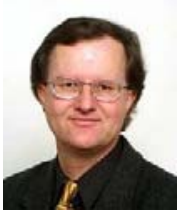

Magnus Willander has M.Sc degrees from Lund University, (physics), Uppsala University (engineering physics) and Stockholm University (economy) and $\mathrm{PhD}$ degree in physics from Royal Institute of Technology in Stockholm. Dr Willander worked five years with electronic design in different industries in the 70s and 80s. In the 80 s he did pioneering work on $\mathrm{SiGe}, \mathrm{SiC}$ and polymer transistors as associate professor in Linköping University. In 1995 he was appointed to full professor in nanoscience in Gothenburg University, where he continued to work on more fundamental problems related to tunneling, collective phenomena like BEC, stochastic phenomena etc. In the beginning of 2000 Prof. Willander extended his work to more soft materials and liquids. Around 2002 he started his work on $\mathrm{ZnO}$ nanostructures. In 2005 Willander become professor in Linköping University where he has continued to work on $\mathrm{ZnO}$ nanostructures and its interaction with soft materials etc. During 2006 and 2009 he was also guest professor in Gothenburg University. He has also several times been guest scientist in nanoscience in Tokyo Institute of Technology, Tokyo. In the 
above mention research areas Prof. Willander has published numerous numbers of experimental and theoretical refereed articles and eight books.

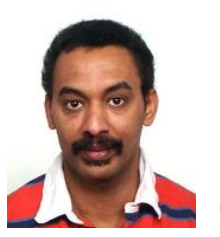

Omer Nur completed the B.Sc. Honors in Physics during 1986 from the University of Khartoum, Sudan and the Ph.D. degree during 1996 in Device Physics from the University of Linköping, Sweden. His research interest is in device physics and technology. At present Dr. Omer Nur is an associate professor and holds a senior lecturer position at the Department of Science and Technology, Campus Norrköping, Linköping University, Sweden. His current research interest is synthesis, characterization and device development based on $\mathrm{ZnO}$ nano-structures for technical and medical applications. He has published over 120 articles in international journal and in reviewed conference proceedings.

Bengt Danielsson joined Pure and Applied Biochemistry, Lund University 1975 realizing various biosensor developments, such as the 'enzyme thermistor' and "enzyme transistors". He became $\mathrm{PhD}$ in biochemistry 1979 and associate professor (docent) in biochemistry 1982. He joined the medtech company Acromed Invest in Lund 2007. His current research interests are focused on bioanalysis and biosensor development and practical biomedical and environmental applications including miniaturized sensor-chips for home and in and ex vivo monitoring. Studies on thermometric and optical sensors as well as electrochemical and optothermal techniques has resulted in about 300 publications. Recent work involves nanotechnology (e.g. ZnO nanowires), bioaffinity arrays and micropattern formation studied by surface plasmon resonance, ellipsometry, scanning probe microscopy and chemiluminescent and fluorescent immuno- and molecular imprinting assays.

Salah Salman is a research assistant with Prof, Bengt Danielsson at Acromed Invest AB, Magistratsvägen 10, SE-22643 Lund, Sweden. 